\title{
RESHAPING EDUCATIONAL SYSTEMS TO REALIZE THE PROMISE OF INCLUSIVE EDUCATION
}

\author{
Jeong Hoon Choi ${ }^{1}$ \\ University of Kansas, USA \\ Amy B. McCart \\ University of Kansas, USA \\ Wayne Sailor \\ University of Kansas, USA
}

\begin{abstract}
Inclusive educational practices are rooted in a body of research indicating that when students in need of support through special education are meaningfully included in schools, academic and social outcomes improve for all students. To realize this promise of better outcomes, traditional schools with separate classrooms and even schools designated to exclusively serve various learner subgroups (e.g., students identified for special education) will require reorganized systems, structures, and resources. A school with a fully integrated educational framework is better positioned to meet the needs of all students, including those who live in poverty, who experience high mobility, who benefit from an accelerated curriculum, or who struggle to learn for other reasons. This paper describes an example of a transformational framework and technical assistance provided to a whole interlocking education systems (i.e., state, district, school) to reshape and increase school capacity to implement and sustain an equity-based, inclusive multi-tiered system of support. Statistical analyses that compared academic achievements of students with Individualized Education Programs (IEPs, i.e., disability) in schools reflecting early stages of transformation with that of students with IEPs in schools reflecting advanced transformation. The extent of school transformation to the framework significantly predicted improved outcomes for students with IEPs.
\end{abstract}

Keywords: inclusion, school reform, multi-tiered system of support, MTSS

\footnotetext{
${ }^{1}$ Correspondence: The University of Kansas, 1314 Wakarusa Drive, Suite 208, Lawrence, KS 66045, USA; Email: yes5150@ku.edu.

Acknowledgement: This data in article was produced under U.S. Department of Education, Office of Special Education Programs Grant No. H326Y120005, University of Kansas. Grace Zamora Duran and Tina Diamond serve as the OSEP project officers. The views expressed herein do not necessarily represent the positions or policies of the U.S. Department of Education. No official endorsement by the U.S. Department of Education of any product, commodity, service or enterprise mentioned in this publication is intended or should be inferred.
} 


\section{Reshaping Educational Systems to Realize the Promise of Inclusive Education}

Special education in the U.S. began in earnest with passage of the Education of the Handicapped Amendments (EHA) to the Elementary and Secondary Education Statute (ESEA), passed by Congress and signed into law by President Ford in 1975. The proposed funding from Congress included up to $40 \%$ of the cost of educating students with disabilities to be paid by the federal government with the balance to be shouldered by state and local entities. During nearly five decades of special education law, the $40 \%$ target never came close to being realized. At present, the federal contribution is approximately $15 \%$. Moreover, the basic framework of special education with its categorical descriptive language structure remains essentially unchanged for the past half century of praxis.

None of the above would be grounds for contention if results were promising. They are not. By almost any yardstick, post-graduation quality of life issues for individuals served under special education law in the U.S. are relatively, and in some cases extremely, dismal (Newman et al., 2011). Meaningful change is needed to improve long range quality of life outcomes for students addressed through resources provided under Public Law 108-446, the Individuals with Disabilities Education Improvement Act of 2004, or IDEA, as it is generally referenced. The purpose of the research reported in this paper is to present some preliminary results from implementation of an alternative framework for education, one that fully encompasses and integrates special education and all other categorical "silos" into a unified system of education for all children, while remaining consistent with extant U.S. federal laws and regulations.

The framers of the first special education laws recognized that it might lead to construction of a separate system of education for students labeled as having one or more disabilities. Therefore, they introduced the concept of the least restrictive environment, often referred to as LRE, linked to a complex eligibility determination process, and they used of the term "placement" to describe various environments. To receive federal special education funding, state education agencies had to report the proportion of students served in placement options ranging from fully integrated into general education (i.e., grade-level class) to totally segregated (i.e., special class, special school, special school district). This regulatory requirement led to acceptance by the field of the concept of a "continuum of placements" that could be employed by school districts when deciding what the least restrictive environment would be for particular students. This idea persists today, although no law mandates that school districts must maintain various placement options. Further, despite a long history of federal lawsuits, Supreme Court decisions, U.S. Department of Education policy imperatives and a preponderance of research evidence challenging the utility of segregated placements, widespread categorical segregation of students identified for special education continues to this day (U.S. Department of Education, National Center for Education Statistics [NCES], 2017).

Recent data suggest that some progress is evident in providing greater access to the general education curriculum for students considered to have high incidence or "mild and/or moderate" disabilities (NCES, 2017; Rojewski, Lee, \& Gregg, 2015). However, for students considered to have low incidence, or "severe" disabilities, few opportunities exist to learn from the general education curriculum alongside non-disabled peers (Kurth, Morningstar, \& Kozleski, 2014; NCES, 2017). We question the premise of the dichotomy between "disabled" and "non-disabled" children. This distinction leads to significant expenditures of federal and state funds directed to determination of student eligibility for special education; funds that are sorely needed in the realm of praxis (e.g., Koski, 2017). 
Much of the somewhat contentious discourse around least restrictive environment has been linked to the term "inclusion." This term, which began to appear in special education research literature in the $1980 \mathrm{~s}$, became identified with a quasi-resistance movement that emerged in response to increasing segregation of students identified for special education (Skrtic, 1991; Skrtic, Sailor, \& Gee, 1996). Various models for implementing inclusion emerged during this period, and several continue to be advanced today (Mitchiner, McCart, Kozleski, Sweeney, \& Sailor, 2014). What virtually all such models have in common is a focus on the place where education is imparted. These models take the form of designing ways that students served in a self-contained environment with Individualized Education Programs (IEPs) can increase time in a grade-level or content-specific general education classroom. These approaches have engendered ongoing criticism from sectors of the special education research communities and practitioners, who have argued forcefully for concentrated services in self-contained settings (Kauffman, McGee, \& Brigham, 2004). The inclusion movement, while making progress with students labeled as having mild or moderate disabilities, has been largely unsuccessful with students labeled as having "severe" disabilities (Kurth et al., 2014).

The place-based definitions of inclusion are further buttressed by the federal reporting system for measuring inclusion by the least restrictive environment placement options. The yardstick is pegged at "percentage of time in the general education classroom" with reporting categories set as " $80 \%$ or more in general education"; " $40-79 \%$ "; "Less than $40 \%$." The reporting requirement focused on a single environment, the general education classroom, problematizes the place-based inclusion agenda. Seating students in the room during reading time or an algebra class when they are not engaged in the curriculum content is counterproductive to the students, the teacher, and quite possibly entire class. However, issues impeding those students' engagement need not constitute grounds for segregating them in a self-contained, disability-only environment.

The advent of whole-school Multi-Tiered System of Support (MTSS) creates an opportunity to reframe the concept of inclusion such that the general education classroom is one of several integrated educational environments available for instruction within a tiered framework for instruction. Students with specialized need for supports and services might be in the grade-level classroom for those portions of the curriculum in which they can be measurably engaged under Universal or Tier 1 level of instruction, or even with an additional, Tier 2 level of support within the classroom; and in other integrated environments within the confines of the school and, perhaps, the surrounding community in the case of higher grade-level students. MTSS thus raises the possibility of eliminating self-contained classrooms for any students, including those who receive support from special education, gifted, language acquisition, and other programs. The net result of full implementation of MTSS under a reframed, equity-based definition of inclusion is that every student engages the general education curriculum in a measurable format in accordance with a flexible master schedule; a more effective and efficient use of all paid school staff and volunteers; a more efficient use of all existing school space; and utilizing three tiers of intensity of instruction directed to academics, behavior, and social-emotional development (Lane, Oakes, \& Menzies, 2019; McCart \& Miller, 2020).

Grounded in the scholarship of Artiles, Kozleski, and colleagues (2006; 2016), we call this reframed inclusion concept equity-based inclusive MTSS. The focus under a whole-school MTSS framework is less concerned with including students (because we assume from the beginning that all are included), and is more concerned with including staff, supports, and

services in an equitable manner such that each and every student receives whatever needed supports are available, from whatever source. The issue for educators is forming an 
instructional match between the measured instructional needs of students and the best educational supports and or services available to the school that will enable successful engagement with various elements of the curriculum (Burrello, Sailor, \& KleinhammerTramill, 2013).

The construct of disability further problematizes inclusion by any definition. Special education was originally framed as a medical-model profession (Massoumeh \& Leila, 2012). Issues of impediments to learning are considered to be lodged within the individual. These endemic limitations can be categorized (e.g., autism, severe behavior disorder, specific learning disability). If their impediments are labeled as severe, students are typically routed, through diagnosis and referral, into specialized curricula delivered to them in self-contained classrooms or schools. General educators are often taught in their pre-service programs that the presence of one or more disabilities in a student renders that student someone else's problem, namely a special education teacher. Special educators are prepared to address students' learning needs based on the categorical label affixed to the student in a disability determination process. Student learning needs, however, are frequently a poor fit for the category to which they are assigned. This reality renders the federal reporting categories in special education grossly unreliable (Skrtic, 2005). The problem of over representation of ethnic minorities is an example of a failure of the categorical placement system (Artiles, Kozleski, Dorn \& Christensen, 2006; Cooc \& Kiru, 2018).

We argue that the time has come, through the advent of whole-school, equity-based inclusive MTSS, to replace the medical model construct of disability with a human capability construct that reflects the significant contribution of the learning ecology to individual students' response to instruction (Burrello et al., 2013). As such, the human capabilities frame represents a sociological model that reflects the importance of school organization, both space and personnel considerations, in creating an interactive match between characteristics of the student affecting learning and characteristics of the teaching/learning ecology. Many years ago, the psychologist Kurt Lewin (1936) introduced the concept as a simple formula, known as Lewin's equation: behavior is a function of the person and the environment, that is, $\mathrm{B}=f(\mathrm{P}, \mathrm{E})$.

All of the above said, establishment and implementation of schoolwide MTSS is no easy task. It implies nothing less than a complete transformation of school from "business as usual" to a new form (Sailor, 2017). The National Technical Assistance Center on Inclusive School Reform, which was funded by the U.S. Department of Education, Office of Special Education Programs (OSEP) from 2012 to 2018, assisted 64 schools in 17 school districts within 5 states to install, implement, sustain and scale-up schoolwide MTSS under a scaffolded framework called SWIFT for Schoolwide Integrated Framework for Transformation (Sailor, 2012). The Center selected four domains of practice for which a body of evidence existed suggesting that, compiled together, would serve as a "scaffold" to enhance the transformational effort. These scaffolding domains are: Administrative Leadership, defined as strong and engaged site leadership and strong educator support system; Integrated Educational Framework, defined as fully integrated organizational structure and a strong and positive school culture; Family and Community Engagement, defined as trusting family partnerships and trusting community partnerships; and Inclusive Policy Structure and Practice, defined as strong LEA/school relationship and an LEA policy framework (McCart, Sailor, Bezdek, \& Satter, 2014). A fidelity of implementation tool called SWIFT-FIT (MorsbachSweeney, Horner, Algozzine et al., 2014) was developed and standardized. This tool was administered across the implementing schools at least once per year beginning in 2014 to document progress in implementation and to use when estimating the framework's impact 
on student academic and behavioral outcomes through modeling and regression (e.g., Kozleski \& Choi, 2018; Kurth, Morningstar, \& Hicks, 2018; Sailor, McCart, \& Choi, 2018).

Since the inception of the SWIFT framework, other potential scaffolding supports are beginning to emerge in the research literature. Charlton, Sabey, Dawson, Pyle, Lund, and Ross (2018), for example, reported a qualitative investigation of state MTSS scale-up efforts in 27 states to ascertain which educational practices were perceived by administrators as "helping categories" for MTSS implementation, and which could be identified as "hindering categories." Helping categories included: multi-disciplinary leadership, access to professional development, consistent language practices, consultation with external partners, and a focus on student outcomes. For example, the California Department of Education awarded a contract to the Orange County Department of Education (OCDE) in 2016 to create an infrastructure of county and district-level support to schools to begin scale up implementation of MTSS in each of the state's more than 1,000 school districts, with a potential reach of up to 10,000 schools in the first wave of the work (www.camtss.org). OCDE partnered with a rural county office, Butte County Office of Education (BDOE), and with SWIFT Education Center at the University of Kansas to define a California-specific MTSS framework and train personnel to support implementation in schools through a "mini grant" process. These important MTSS efforts have affected the way in which schools provide education, how districts sustain educational efforts, and how states support districts.

The SWIFT framework for providing technical assistance to whole education systems (i.e., state, district, school) to reshape and increase the system's capacity through MTSS to implement, scale up, and sustain integrated, inclusive education to enhance academic success for all students has an evidence base for overall student outcomes (Sailor, McCart, \& Choi, 2018). The purpose of this study was to investigate the efficacy of this equity-based framework on academic achievement for students with IEPs.

We begin with a summary of overall changes of the proficiency status (i.e., students who met the proficiency standard) for all participating schools and then report results of statistical analyses for a particular state to examine outcomes of the study. The analyses were conducted to address the following research questions.

Research Question \#1. What is the probability of students with IEPs being proficient in English Language Arts (ELA) and math over time?

Research Question \#2. Do probabilities of this student group being proficient in ELA and math change over time?

Research Question \#3. What do these students' ELA and math proficiency trends look like over time?

Research Question \#4. Does implementation with fidelity explain these students' likelihood of being proficient in ELA and math over time?

\section{Method}

\section{Participants}

SWIFT researchers purposively selected 5 state education agencies (SEAs) based on self-assessed readiness for the transformation effort, including their current policy, organizational, demographic, and performance context and needs (Mitchiner, 2014). After 
the SEAs were engaged, they nominated 17 local educational agencies (LEAs or districts); and finally the LEAs nominated the 64 kindergarten through 8 th grade-level schools. Due to administrative turnover in participants, 54 schools among the original 64 consistently participated in SWIFT implementation from 2013-14 through 2016-17 school years.

Academic proficiency changes were investigated with data from students with IEPs in consistently implementing schools that took the same state assessment for two years $(n=$ 1,131 for ELA; $n=1,119$ for math). Since all states changed their annual state assessment tests during the four implementation years, only the last two years data were available to study as consecutive years in which each state administered the same state assessment. Table 1 provides the standardized assessment, number of participating schools, the grade-level range served, Title I status, and number of students with IEPs by state.

Table 1

Schools that Administered the Same State Assessment and Participated in the Equity-based Inclusion Implementation for Two Consecutive Years

\begin{tabular}{|c|c|c|c|c|c|}
\hline \multirow{2}{*}{$\begin{array}{l}\text { State } \\
\text { A }\end{array}$} & \multirow{2}{*}{$\frac{\text { LEAs }}{4}$} & \multicolumn{2}{|c|}{ Schools by Grade level served } & \multirow{2}{*}{$\frac{\text { Title I Schools }}{14}$} & \multirow{2}{*}{$\frac{\text { Total Schools }}{16}$} \\
\hline & & Elementary & 9 & & \\
\hline & & Middle & 5 & - & - \\
\hline & & PK or KG -8 & 2 & - & - \\
\hline \multirow[t]{3}{*}{ B } & 4 & Elementary & 11 & 16 & 16 \\
\hline & & Middle & 5 & - & - \\
\hline & & PK or $K G-8$ & 0 & - & - \\
\hline \multirow[t]{3}{*}{$\mathrm{C}$} & 4 & Elementary & 5 & 8 & 8 \\
\hline & & Middle & 2 & - & - \\
\hline & & PK or $\mathrm{KG}-8$ & 1 & - & - \\
\hline \multirow[t]{3}{*}{$\mathrm{D}$} & 4 & Elementary & 11 & 8 & 16 \\
\hline & & Middle & 2 & - & - \\
\hline & & PK or $K G-8$ & 3 & - & - \\
\hline \multirow[t]{3}{*}{$\mathrm{E}$} & 1 & Elementary & 2 & 5 & 5 \\
\hline & & Middle & $\mathrm{O}$ & - & - \\
\hline & & PK or $K G-8$ & 3 & - & - \\
\hline
\end{tabular}

Note: PK or KG-8 = pre-Kindergarten or Kindergarten through 8 th grade

The statistical analyses were conducted with schools in "state A" because it was the only participating state that administered the same state assessment (i.e., Partnership for Assessment of Readiness for College and Careers [PARCC]) for the longest number of consecutive implementation years (i.e., 3 out of the 4 implementation years); and all schools in this state consistently participated in the implementation throughout the 4 years. State A had a total of 16 participating schools; however, data from 15 schools were analyzed because one school had no students with IEPs assessed by PARCC for three consecutive school years. Thus, the analysis includes 214 students with IEPs who took PARCC for the three 
consecutive years. About $58 \%$ of the students in these schools were White, $31 \%$ African American, $4 \%$ Hispanic, and $7 \%$ were multi-race. About $71 \%$ of these students were receiving free or reduced-price lunch due to family low socio-economic status.

\section{Measurements}

SWIFT-FIT. This assessment was designed to measure the fidelity of the framework's implementation status. Trained assessors visited schools and spent a full day administering SWIFT-FIT. Assessors conducted interviews with the leadership team, educators, parents, and other staff; reviewed documents; and observed classrooms to gather information to score fidelities for the total mean and sub-scales for 10 features nested in 5 domains. As part of the technical assistance process, the results of SWIFT-FIT assessments were shared with each school leadership team to identify strengths and opportunities for improvement at their school.

SWIFT-FIT is a valid and reliable assessment for assessing equity-based, inclusive MTSS implementation (Algozzine et al., 2016). Its preliminary technical adequacy study indicates that the average Content Validity Index (CVI) for SWIFT features ranged from 0.87 (for Strong Educator Support System) to 1.0 (for Fully Integrated Organizational Structure and Trusting Family Partnership), which suggests evidence of expert validity (Lynn, 1986; Polit \& Beck, 2006). Internal consistency analysis results revealed that Cronbach's Alpha for the SWIFT-FIT total mean score was 0.96, and an average inter-rater agreement was $82.3 \%$. Construct validity was analyzed by comparing six exemplifying effective schools and sampled initial partner schools, and results showed that the sampled initial partner school score $(M=37.83, S D=11.34)$ was significantly different from the exemplifying effective school score $(M=57.94, S D=15.69), t=-2.32, p<0.05, E S=1.77$. Its usability was assessed by checking SWIFT-FIT's ease of use for assessors; an overall mean of 3.1 was obtained out of 4 (i.e., a 4-point Likert scale) (Algozzine et al., 2016).

State summative assessments. As an annual state standardized academic assessment State A administered PARCC, which is one of the two major Common Core consortia. PARCC is considered to be a valid and reliable tool to measure proficiency of grade-level Common Core standards (PARCC, 2016). Initially, a total of 11 states and the District of Columbia were administrating PARCC. Smarter Balanced Assessment Consortium (SBAC), the other major Common Core consortia, was consistently administered for the last two years of implementation in States C, D, and E. SBAC aligns with common core state standards and the official psychometric report documents its technical adequacy (SBAC, 2016). For State B, their own state assessment was administered for the final two years of implementation. This assessment was designed to measure student achievement on the state's College-and CareerReadiness Standards for ELA and math, and was conducted with the aim of providing valid and reliable results with which to guide instruction through data-based instruction.

Results for ELA and math were collected and analyzed across all states. The overall proficiency status change analysis utilized all states' assessment data collected from the final two implementation years, and the statistical analysis focused on the three-year longitudinal PARCC data from State A.

\section{Practices and Procedures}

Equity-based, inclusive MTSS installation began in 2013-14 and continued with assistance through 2016-17 school year. The differentiated, intensive technical assistance provided by SWIFT Education Center for equity-based, inclusive MTSS was designed to sustainably improve student outcomes. Six major transformation in action practices were 
employed: (a) design/visioning, (b) data snapshot reviews, (c) priority and practice planning, (d) resource mapping and matching, (e) teaming, and (f) coaching (for more information, see McCart, McSheehan, Sailor, Mitchiner, \& Quirk, 2016). Through these practices, schools built a shared understanding about their ideal future with respect to inclusive education. Using schoolwide student data and other measures of organizational capacity, they reviewed their strengths and opportunities for achieving their vision. They set priorities for the next few months and created action plans. In the meantime, they mapped out their available resources (e.g., building space, staff, or other untapped resources) and then matched them with planned actions, reorganizing and reallocating resources when needed. They used teaming practices and received coaching support as overarching transformation practices. Teams connected multiple organizations with communication strategies, while coaching maintained ongoing intensive relationships between technical assistance providers and school teams as they installed MTSS and the scaffolding domains (McCart et al., 2016). SWIFT Education Center also hosted a 3-day intensive professional learning institute (PLI) at the beginning of implementation, and 2-day PLIs were held regionally or nationally each year after that. The PLIs included school, LEA, and SEA leadership teams to provided necessary knowledge and skills for equity-based inclusion (e.g., sessions for essentials of academic and behavior MTSS, Universal Design for Learning (UDL), differentiated instruction, family engagement, and so on). The technical assistance providers also had weekly meetings with school principals and LEA staff to exchange information and build LEA leadership team meeting agendas as the practices became naturally embedded in their regular bi-weekly leadership meeting agendas.

\section{Data Analysis}

First, we analyzed overall proficiency status change using descriptive statistics (i.e., number and percentage of students who met proficiency standards) among students with IEPs who took the state assessments for the two consecutive implementation years as described above. Second, we analyzed three-year longitudinal data using logistic generalized estimating equation analyses and linear mixed-model analyses for the dichotomous outcome (i.e., met the proficiency standard or not). In examining the effect of implementation with fidelity, ROC curve analyses were conducted to find optimum cut-off points of SWIFT-FIT for PARCC ELA and math scores. A dichotomous variable was created to distinguish schools that met the fidelity standards and those that did not.

We began with a basic model including main effects for time (i.e., school year), then added the implementation fidelity status, and next added the time by fidelity status for the interaction effect. Time was treated as a categorical variable to assess implementation effects at the different time points, which were school years in this analysis. The cut-off score of SWIFT-FIT for PARCC ELA was $64 \%$ for both ELA and math, and a dichotomous variable for schools' implementation fidelity (i.e., above or below 64\%) served as a covariate. The estimated main effects for implementation at different years and interaction effects between implementation with fidelity and year under the different models were presented as odds ratios with $95 \%$ confidence intervals for remission rates.

The repeated-measures outcomes in two parameters were specified to describe the intercept and time-related slopes as follows.

$$
\begin{aligned}
& \eta_{t i}=\log \left(\pi_{t} d\left(1-\pi_{t i}\right)\right)=\beta_{0}+\beta_{1} \text { time } \\
& \eta_{t i}=\log \left(\pi_{t} /\left(1-\pi_{t i}\right)\right)=\beta_{0}+\beta_{1} \text { time }+\beta_{2} \text { fidelity }
\end{aligned}
$$


In Equation 1, time is coded to indicate the interval between successive measurements, where $\eta_{\mathrm{ti}}$ is the underlying transformed predictor of the dichotomous response at time $t$ for individual $i, \beta_{0}$ is an intercept, and $\beta_{1}$ describes the rate of change on a logit scale in the fraction of positive responses in the population of subjects per unit time. The between-subject predictor (i.e., SWIFT fidelity) is added in Equation 2. The predicted probability of proficiency can be calculated from the following equation.

$$
\pi_{\mathrm{ti}}=1\left(1+e^{-\left(\eta_{t i}\right)}\right)
$$

\section{Results}

\section{Overall proficiency status change}

Based on observed data, the proportions of students with IEPs meeting proficiency standards in state summative assessments increased for both ELA and math across the two years of implementation (i.e., 2015-16 and 2016-17 school years). A total of 1,131 students with IEPs from 61 schools participated in both years' ELA, and the proportion of students who met the proficiency standard increased from $12.0 \%(n=136)$ to $13.1 \%(n=148)$. For math, 9.7\% students $(n=109)$ out of 1,119 met the proficiency standard in the 2015-16 school year, and the proportion increased to $11.1 \%$ in the 2016-17 school year. Table 2 shows the number and proportion changes.

\section{Longitudinal impact of equity-based inclusion on proficiency}

Recall that logistic generalized estimating equation analyses and linear mixed-model analyses were conducted to examine the probabilities of students with IEPs being proficient (i.e., research question (RQ) \#1), its change (i.e., RQ \#2) and trends (i.e., RQ \#3), and its relationship with implementation fidelity (i.e., RQ \#4). The results of this analysis revealed that the likelihood of students with IEPs being proficient significantly increased during the implementation period. Further, the students in schools that implemented the framework with fidelity had a significantly larger probability of being proficient than those in schools that did not meet minimum fidelity standards. These results were found for both ELA and math scores.

In the basic model for the overall School Year effect, students' likelihood of being proficient increased significantly over each interval for both ELA $(\log$ odds $=0.54, p<0.001)$ and math $(\log$ odds $=0.51, p<0.001)($ see Model I in Table 2$)$. The odds ratio showed that individual students are almost 0.04 times more likely to be proficient than non-proficient at the beginning year of the study (i.e., 2014-15 school year) for both ELA and math. The initial proportion of students who were proficient in ELA at the beginning of the trend was about $3.3 \%$, which was calculated by Equation 3. For math, the initial proportion was about 3.7\%.

The growth trends were analyzed in Model II. At the second school year (i.e., 201516 ; $\log$ odds $=0.999, p<0.01$ ) and the third school year (i.e., 2016-17; $\log$ odds $=1.22, p<$ $0.001)$, students were significantly higher in the probability of being proficient in ELA relative to their proficiency status at the first school year (i.e., 2014-15). The odds of being proficient at the second year versus the first year were multiplied by 2.716 (or increased by $171.6 \%$ ). At the third year, the odds of being proficient were multiplied by 3.39 (or increased by $238.8 \%$ ) compared to the first year. The estimated probability of being proficient at the second year was about $8.4 \%$, and the probability at the third year was $10.3 \%$. The same improvement in probability was observed in math. The log odds at the second year was 0.73 
$(p<0.05)$ and third year was $1.08(p<0.001)$, which suggested a higher probability of being proficient compared to the first year. The estimated probability of being proficient at the second year was $7.3 \%$ and the third year was $10.1 \%$.

Figure 1.

Proportion of students with IEPs who met PARCC proficiency standard in schools implementing equity-based, inclusive MTSS with fidelity and without fidelity each year. Please note that the number of schools implementing with fidelity changed each year. Among the 15 schools, 4 schools were implementing with fidelity in SY2014-15; 12 schools in SY2015-16; and 11 schools in SY2016-17.

\section{Proportion of Students with IEPs Met Proficiency Standard \\ PARCC ELA}

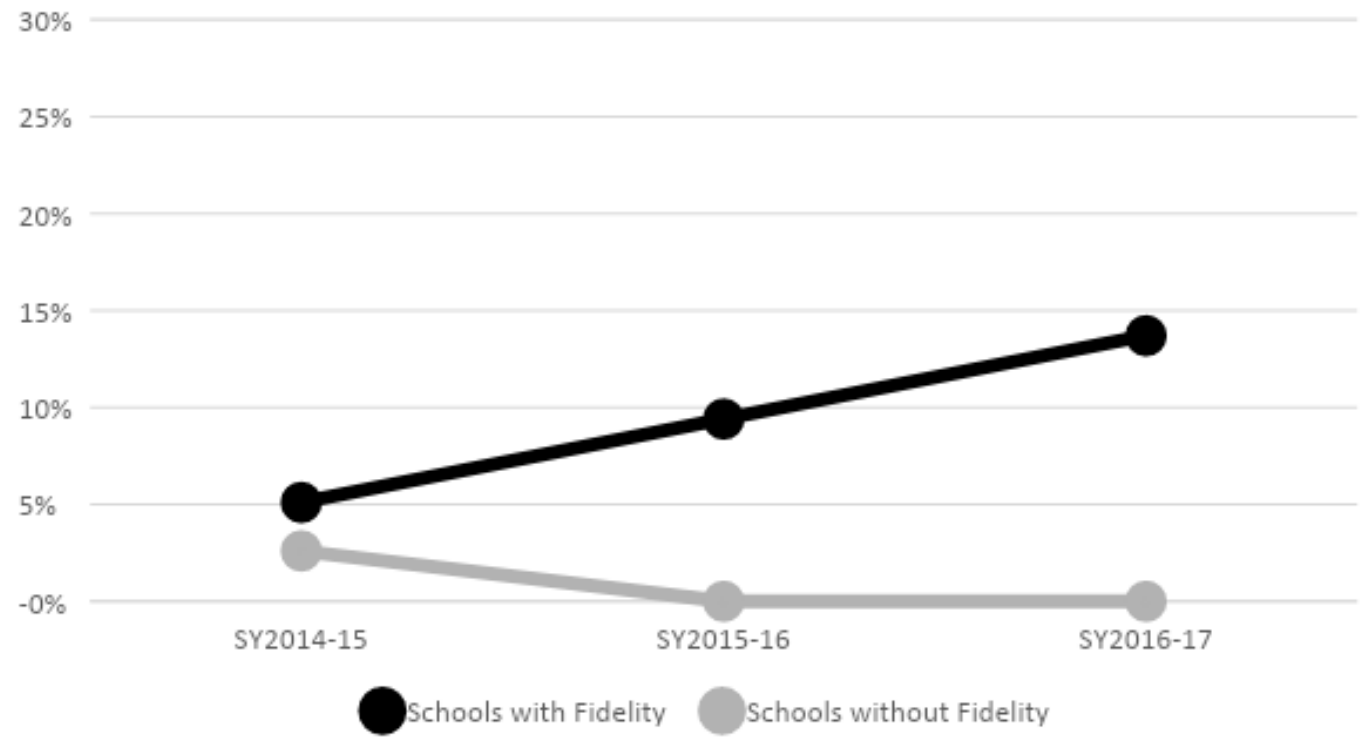

(figure continues)

PARCC Math

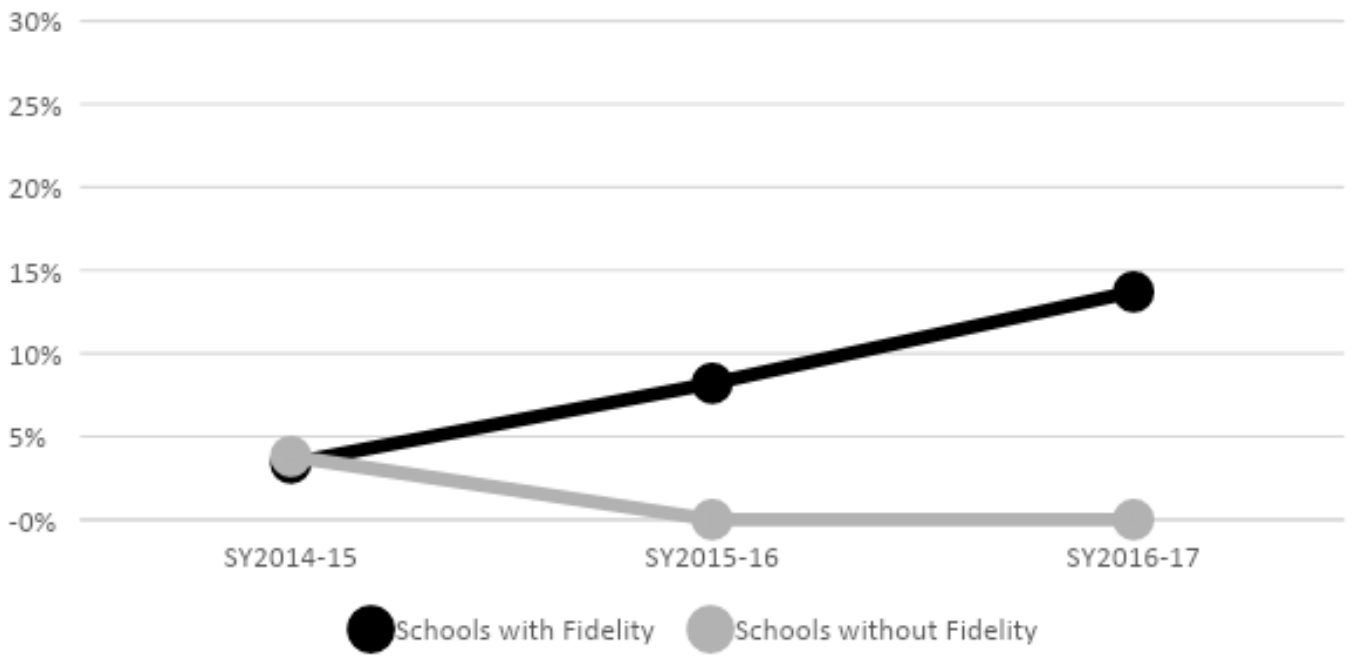


In the model for the impact of meeting implementation fidelity (i.e., Model III in Table 2), students with IEPs in the schools that met implementation fidelity (i.e., schools that scored $64 \%$ or higher on SWIFT-FIT) were more likely to be proficient in PARCC than those in schools that did not meet fidelity (i.e., scored less than 64\%) at the first year (i.e., 2014-2015). For ELA, the likelihood of students with IEPs being proficient in schools that did not implement with fidelity was -3.66 and the estimated probability was about $2.5 \%$. In contrast, for schools that met fidelity, the likelihood of being proficient at initial status was -2.88 and the estimated probability was about $5.5 \%$, which was higher than schools that did not meet fidelity. The analysis for math did not reveal a significant effect of implementation fidelity $(\log$ odds $=0.38, p=0.13)$ while other variables were controlled. Year effect was still significant $(\log$ odds $=0.44, p<0.01)$ for math.

To investigate the longitudinal impact of meeting implementation fidelity on the students with IEPs being proficient, covariate interactions were added to the model. Results of the final model (see Model IV in Table 2) showed that the interaction effects with high SWIFT-FIT (i.e., 64\% or higher) were significant and positive in both ELA and math. This finding could be interpreted to mean that change in student proficiency status over time is linked to SWIFT-FIT scores representing the extent to which the equity-based, inclusive education framework is implemented in the school. More specifically, over time, the probability of students in schools with high SWIFT-FIT scores (i.e., 64\% or higher) being proficient improved more sharply than among peers in low SWIFT-FIT score schools $(\mathrm{p}<$ 0.001). In particular, the odds of being proficient for students in schools that met fidelity (i.e., $64 \%$ or higher) were multiplied by 3,775 for each yearly interval. The same results were observed, and odds were even higher for math. The odds of being proficient in schools that met fidelity were multiplied by 147,165 for each interval for math. Figure 1 depicts the interaction effect, in which different proportion growth of students with IEPs met the proficiency standard for schools that implemented with and without fidelity.

\section{Discussion}

The current study investigated longitudinal changes of PARCC proficiency in ELA and math for students with IEPs who consistently enrolled in schools implementing an equity-based, inclusive MTSS framework. Results of descriptive analysis indicated that the proportion of students with IEPs who met the proficiency standard increased in both ELA and math during the two consistently measurable years of education in schools using this framework. With schools in one state with three years of longitudinal data, logistic generalized estimating equation analyses and linear mixed-model analyses results showed that students were 0.04 times more likely to be proficient than non-proficient for both ELA and math at the beginning of the study year, and the likelihood increased significantly over each year. The growth trends showed that the estimated probability of being proficient continuously increased at the second and third study years in ELA and math. Finally, the change in probability of students being proficient in ELA and math was significantly related to implementation the MTSS framework with fidelity.

This study sought to examine the efficacy of educating students receiving supports and services through special education, who were fully included within a whole-school, equity-based operational definition of inclusion as a component of an MTSS framework. A fidelity of implementation tool was used to compare schools in early stages of transformation, that is, still reliant on traditional, categorical, place-based inclusion tactics such as "push in pull out," separate class placement or seating students in a general education classroom without enough pedagogical resources to engage them in curriculum activities; with schools 
in later stages of transformation wherein students with IEPs were educated alongside their general education peers in fully integrated school environments and were fully exposed to the general education curriculum through inclusive instructional strategies. The fidelity tool (SWIFT-FIT) differentiated schools fully implementing equity-based, inclusive MTSS practices from those implementing traditional place-based practices. The statistical analysis provided suggestive evidence for enhanced outcomes in ELA and math over time for students in schools implementing the MTSS framework with fidelity.

The findings of the current study must be interpreted with caution in light of several limitations. Data analyzed in the study were derived from a grant-funded technical assistance project and therefore may not be generalizable to all students with IEPs. Sampled students with IEPs in the analyses were purposively selected due to the national change of state summative assessments. This study was able to analyze only the last two implementation years data for the overall proficiency status change, and the three-year longitudinal statistical analyses included schools in only one state. Future randomized controlled trials or waitlistcontrol trials with larger sample sizes will be able to provide better evidence on the efficacy of equity-based, inclusive MTSS practices in the future.

The dependent variable for the current study was limited to academic outcomes of students with IEPs in the current study. Disruptive behavior may play an important role in ELA and math performance on assessments, especially for students with IEPs. Future studies should be conducted on social/behavioral issues that impede student learning and should investigate the relationships among equity-based inclusion (and its fidelity), academic outcomes, and behavior outcomes of students with IEPs to provide a more nuanced evaluation of efficacy as defined in this MTSS framework.

Finally, efficacy investigations of equity-based, inclusive MTSS on students with significant disability who take an alternate assessment based on alternate achievement standards (AA-AAS) need to be conducted in the future. The current study included students with IEPs taking the regular state summative assessment. Findings in the current study, therefore, might not be appropriate to be generalized for students with significant cognitive disabilities who take the AA-AAS.

Although these results are limited, it is noteworthy that through the implementation of equity-based, inclusive MTSS the probability of students with IEPs scoring in the proficient range of the ELA and math state assessments continuously increased as their schools implemented equity-based, inclusive MTSS. 
Table 2

Association Between Academic Proficiency and Equity-based Inclusion Implementation Fidelity

Overtime

\begin{tabular}{|c|c|c|c|c|c|c|c|c|c|c|c|c|}
\hline & \multicolumn{3}{|c|}{ Model I } & \multicolumn{3}{|c|}{ Model II } & \multicolumn{3}{|c|}{ Model III } & \multicolumn{3}{|c|}{ Model IV } \\
\hline & $\mathrm{LO}(\mathrm{OR})$ & $95 \%-\mathrm{CI}$ & $p$ & $\mathrm{LO}(\mathrm{OR})$ & $95 \%-\mathrm{CI}$ & $p$ & $\mathrm{LO}(\mathrm{OR})$ & $95 \%-\mathrm{CI}$ & $p$ & $\mathrm{LO}(\mathrm{OR})$ & $95 \%-\mathrm{CI}$ & $p$ \\
\hline \multicolumn{13}{|c|}{ ELA } \\
\hline Intercept & $-3.14(0.04)$ & $0.02-0.08$ & $<.001$ & $-3.39(0.03)$ & $0.02-0.07$ & $<.001$ & $-3.66(0.03)$ & $0.01-0.06$ & $<.001$ & $-10.61(0.00)$ & $0.00-0.00$ & $<.001$ \\
\hline Year & $0.54(1.71)^{\prime}$ & $1.32-2.21$ & $<.001$ & & & & $0.41(1.51)$ & $1.12-2.03$ & $<.01$ & $-6.50(0.00)$ & $0.00-0.01$ & $<.001$ \\
\hline SY 2015-16 & & & & $1.00(2.72)$ & $1.41-5.22$ & $<.01$ & & & & & & \\
\hline SY 2016-17 & & & & $1.22(3.39)$ & $1.72-6.67$ & $<.001$ & & & & & & \\
\hline Fidelity & & & & & & & $0.80(2.24)$ & $1.24-4.02$ & $<.01$ & $3.26(26.00)$ & $1.83-369.03$ & $<.05$ \\
\hline Year $\times$ Fidelity & & & & & & & & & & $8.24(3,775)$ & $396-35,938$ & $<.001$ \\
\hline \multicolumn{13}{|c|}{ Math } \\
\hline Intercept & $-3.16(0.04)$ & $0.02-0.08$ & $<.001$ & $-3.27(0.04)$ & $0.02-0.08$ & $<.001$ & $-3.38(0.03)$ & $0.02-0.07$ & $<.001$ & $-7.85(0.00)$ & $0.00-0.00$ & $<.001$ \\
\hline Year & $0.51(1.66)$ & $1.29-2.15$ & $<.001$ & & & & $0.44(1.56)$ & $1.18-2.05$ & $<.01$ & $-9.68(0.00)$ & $0.00-0.00$ & $<.001$ \\
\hline SY 2015-16 & & & & $0.73(2.01)$ & $1.17-3.68$ & $<.05$ & & & & & & \\
\hline SY 2016-17 & & & & $1.08(2.95)$ & $1.66-5.23$ & $<.001$ & & & & & & \\
\hline Fidelity & & & & & & & $0.38(1.46)$ & $0.90-2.37$ & 0.13 & $-0.52(0.60)$ & $0.02-17.80$ & 0.77 \\
\hline Year $\times$ Fidelity & & & & & & & & & & $\begin{array}{l}11.90 \\
(147,165)\end{array}$ & $\begin{array}{l}12,499- \\
1,732,730\end{array}$ & $<.001$ \\
\hline
\end{tabular}

Note: $n=214$ students with IEPs who participated in PARCC for 3 consecutive school years

$\mathrm{LO}=\log$ odds; $\mathrm{OR}=$ odds ratio 


\section{References}

Algozzine, B., Sweeney, H. M., Choi, J. H., Horner, R., Sailor, W., McCart, A. B., ... Lane, K. L. (2016). Development and preliminary technical adequacy of the schoolwide integrated framework for transformation fidelity of implementation tool. Journal of Psychoeducational Assessment, 35, 302-322. doi:10.1 177/0734282915626303

Artiles A., Kozleski E., Trent S., Osher D., Ortiz A. (2010). Justifying and explaining disproportionality, 1968-2008: A critique of underlying views of culture. Exceptional Children, 76, 279-299. doi:10.1177/001440291007600303

Artiles, A. J., \& Kozleski, E. B. (2016). Inclusive education's promises and trajectories: Critical notes about future research on a venerable idea. Education Policy Analysis Archives/Archivos Analíticos de Políticas Educativas, 24, 1-29.

Artiles, A. J., Kozleski, E. B., Dorn, S., \& Christensen, C. (2006). Chapter 3: Learning in inclusive education research: Re-mediating theory and methods with a transformative agenda. Review of Research in Education, 30, 65-108. doi: $10.3102 / 0091732 X 030001065$

Burrello, L., Kleinhammer-Tramill, J., \& Sailor. W. (Eds.). (2013). Unifying education systems. New York: Routledge/Taylor and Francis Group.

Charlton, C. T., Sabey, C. V., Dawson, M. R., Pyle, D., Lund, E. M., \& Ross, S. W. (2018). Critical incidents in the scale-up of state multitiered systems of supports. Journal of Positive Behavior Interventions, doi: 1098300718770804.

Cooc, N., \& Kiru, E. W. (2018). Disproportionality in special education: A synthesis of international research and trends. The Journal of Special Education, 52, 163-173. doi:0022466918772300

Kauffman, J. M., McGee, K., \& Brigham, M. (2004). Enabling or disabling? Observations on changes in special education. Phi Delta Kappan, 85, 613-620. doi:10.1177/003172170408500810

Koski, W. S. (2017). Beyond Dollars? The Promises and Pitfalls of the Next Generation of Educational Rights Litigation. Columbia Law Review, 117(7), 1897-1931.

Kozleski, E. B., \& Choi, J. H. (2018). Leadership for equity and inclusivity in schools: The cultural work of inclusive schools. Inclusion, 6, 33-44. doi:10.1352/2326-6988.6.1.33

Kurth, J. A., Morningstar, M. E., \& Kozleski, E. B. (2014). The persistence of highly restrictive special education placements for students with low-incidence disabilities. Research and Practice for Persons with Severe Disabilities, 39(3), 227-239.

Kurth, J. A., Morningstar, M. E., Hicks, T. A., \& Templin, J. (2018). Exploring the relationship between school transformation and inclusion: A Bayesian multilevel longitudinal analysis. Inclusion, 6, 19-32. doi:10.1352/2326-6988-6.1.19

Lane, K. L., Oakes, W. P. \& Menzies, H. M. (2019). Comprehensive, integrated, three-tiered (CI3T) models of prevention: The role of systematic screening to inform instruction (In Paige C. Pullen and Michael J. Kennedy, Eds., Handbook of response to intervention and multi-tiered systems of support, pp. 63-76). New York: Routledge.

Lewin, K. (1936). Principles of Topological Psychology. New York: McGraw-Hill.

Lynn, M. R. (1986). Determination and quantification of content validity. Nursing Research, 35, 382-385. doi:10.1097/00006199-198611000-00017

Massoumeh, Z., \& Leila, J. (2012). An investigation of medical model and special education methods. Procedia-Social and Behavioral Sciences, 46, 5802-5804. doi:10.1016/j.sbspro.2012.06.518

McCart, A., \& Miller, D. (2020). Leading through equity-based MTSS: Educator practices for all students. Thousand Oaks, CA: Corwin Press. 
McCart, A., McSheehan, M., Sailor, W., Mitchiner, M., \& Quirk, C. (2016). SWIFT differentiated technical assistance (White paper). Lawrence, KS: SWIFT Center. Retrieved from http://www.swiftschools.org/shelf.

McCart, A., Sailor, W., Bezdek, J., \& Satter, A. (2014). A framework for inclusive educational delivery systems. Inclusion, 2, 252-264. doi:10.1352/2326-6988-2.4.252

Mitchiner, M. (2014). Assessing state readiness for change to participate in schoolwide inclusive school reform: A state selection process using broad factors of the Hexagon Tool (Doctoral dissertation). Lawrence, KS. ProQuest Document ID 1651251106.

Mitchiner, M., McCart, A., Kozleski, E., Sweeney, H., \& Sailor, W. (2014). Emerging trends and future directions in effective, inclusive elementary schools for students with extensive support needs. (In J. McLeskey, N. Waldron, F. Spooner, \& B. Algozzine (Eds.), Handbook of research and practices for effective inclusive schools, pp. 477-491). New York: Routledge.

Morsbach Sweeney, H., Horner, R., Algozzine, B., Lane, K., Roger, B., Choi, H., McCart, A., \& Sailor, W. (2014). SWIFT Fidelity of Implementation Tool. Version 1.5. Lawrence, KS: National Center on Schoolwide Inclusive School Reform: SWIFT Center.

Newman, L., Wagner, M., Knokey, A.-M., Marder, C., Nagle, K., Shaver, D., Wei, X., with Cameto, R., Contreras, E., Ferguson, K., Greene, S., and Schwarting, M. (2011). The Post-High School Outcomes of Young Adults With Disabilities up to 8 Years After High School. A Report From the National Longitudinal Transition Study-2 (NLTS2) (NCSER 2011-3005). Menlo Park, CA: SRI International.

Partnership for Assessment of Readiness for College and Careers. (2016). PARCC accessibility features and accommodations manual 2016- 2017 (5th edition). Washington, DC: PARCC Assessment Consortia.

Polit, D. F., \& Beck, C. T. (2006). The content validity index: Are you sure you know what's being reported? critique and recommendations. Research in Nursing $\mathbb{E}^{2}$ Health, 29, 489-497. doi:10.1002/nur.20147

Rojewski, J. W., Lee, I. H., \& Gregg, N. (2015). Causal effects of inclusion on postsecondary education outcomes of individuals with high-incidence disabilities. Journal of Disability Policy Studies, 25, 210-2 19. doi:10.1177/1044207313505648

Sailor, W. (2012). National Technical Assistance Center for Inclusive School-wide Reform. (PR\# H326Y 120005). Washington. DC: U.S. Department of Education, Office of Special Education Programs.

Sailor, W. (2017). Equity as a basis for inclusive educational systems change. Australasian Journal of Special Education, 41, 1-17. doi:10.1017/jse.2016.12

Sailor, W., McCart, A. B., \& Choi, J. H. (2018). Reconceptualizing inclusive education through multi-tiered system of support. Inclusion, 6, 2-18. doi:10.1352/2326-69886.1 .3

Skrtic, T. (1991). The special education paradox: Equity as the way to excellence. Harvard educational review, 61, 148-207. doi:10.17763/haer.61.2.0q702751580h0617

Skrtic, T. M., Sailor, W., \& Gee, K. (1996). Voice, collaboration, and inclusion: Democratic themes in educational and social reform initiatives. Remedial and Special Education, 17, 142-157. doi:10.1177/074193259601700304

Skrtic, T. M. (2005). A political economy of learning disabilities. Learning Disability Quarterly, 28, 149-155. doi:10.2307/1593616

U.S. Department of Education, National Center for Education Statistics. (2017). Digest of Education Statistics, 2016 (NCES 2017-094), Chapter 2. Inclusion of students with disabilities. Retrieved from https://nces.ed.gov/fastfacts/display.asp?id=59 


\begin{abstract}
About the Authors
Jeong Hoon Choi is an Assistant Research Professor and Associate Director of Research and Evaluation at the University of Kansas SWIFT Education Center. He has been involved in various research projects on inclusive education and school system change. His research interests have included leadership, school climate, and student outcomes associated with frameworks such as multi-tiered system of support (MTSS), schoolwide positive behavior support (SWPBS), and schoolwide integrated framework for transformation (SWIFT). His current research is focused on equity-based inclusive education for all students including marginalized students. He is particularly interested in equity-based MTSS, databased decision support system, and related student outcomes. He is co-investigating the Equity Leadership in High Need School research and Data Support System develop research funded through the U.S. Department of Education Office of Elementary and Secondary Education and Institute of Education Sciences.

Amy B. McCart is an Associate Research Professor with Life Span Institute and CoDirector of SWIFT Education Center at the University of Kansas. The focus of her work is to bring about equity in student outcomes by developing high quality, effective instructional leaders who are prepared to improve outcomes for all students, with emphasis on students of color and those with the most extensive need for support. At this writing, she is Co-Principal Investigator for the Equity Leadership in High Need Schools research grant, funded through the U.S. Department of Education Office of Elementary and Secondary Education; and leads a dynamic team of leadership developers working in districts and schools across the nation.

Wayne Sailor is a Professor in the Department of Special Education and Co-Director of the SWIFT Education Center at the University of Kansas. SWIFT Education Center is a resource center, which leads the nation in equity-based MTSS and inclusive education research and services. His academic pursuits are focused on comprehensive school reform with the aim of transforming systems to integrate resources for the benefit of all students through equity-based, inclusive education. He has carried out research within the framework of a multi-tiered system of support, response to intervention (MTSS/RTI), and schoolwide applications of positive behavior interventions and supports (PBIS). He has published extensively in articles and books. His present research and teaching is focused on emancipating marginalized students through comprehensive school reform, emphasizing coherence within and across schools, state agencies, local education agencies and regional systems in aligning systems of support to remove barriers to learning and equitably apply all resources, including new technologies, to all students in whole-school contexts driven by MTSS and UDL strategies.
\end{abstract}

